Article

\title{
Anti-Arthritic and Anti-Inflammatory Potential of Spondias mangifera Extract Fractions: An In Silico, In Vitro and In Vivo Approach
}

\author{
Mohammad Khalid ${ }^{1, *}$, Mohammed H. Alqarni ${ }^{1}$, Ambreen Shoaib ${ }^{2}$, Muhammad Arif ${ }^{3}{ }^{\circledR}$, Ahmed I. Foudah ${ }^{1}(\mathbb{D}$, \\ Obaid Afzal ${ }^{4}{ }^{\circ}$, Abuzer Ali ${ }^{5}$, Amena Ali ${ }^{6}{ }^{\circ}$, Saad S. Alqahtani ${ }^{2}$ and Abdulmalik S. A. Altamimi ${ }^{4}$
}

Citation: Khalid, M.; Alqarni, M.H.; Shoaib, A.; Arif, M.; Foudah, A.I.; Afzal, O.; Ali, A.; Ali, A.; Alqahtani, S.S.; Altamimi, A.S.A. Anti-Arthritic and Anti-Inflammatory Potential of Spondias mangifera Extract Fractions: An In Silico, In Vitro and In Vivo Approach. Plants 2021, 10, 825. https://doi.org/10.3390/ plants10050825

Academic Editor:

Domenico Trombetta

Received: 31 March 2021

Accepted: 18 April 2021

Published: 21 April 2021

Publisher's Note: MDPI stays neutral with regard to jurisdictional claims in published maps and institutional affiliations.

Copyright: (C) 2021 by the authors. Licensee MDPI, Basel, Switzerland. This article is an open access article distributed under the terms and conditions of the Creative Commons Attribution (CC BY) license (https:// creativecommons.org/licenses/by/ $4.0 /)$.
1 Department of Pharmacognosy, College of Pharmacy, Prince Sattam Bin Abdulaziz University, P.O. Box 173, Al-Kharj 11942, Saudi Arabia; m.alqarni@psau.edu.sa (M.H.A.); a.foudah@psau.edu.sa (A.I.F.)

2 Department of Clinical Pharmacy, College of Pharmacy, Jazan University, Jazan 45142, Saudi Arabia; asahmad@jazanu.edu.sa (A.S.); ssalqahtani@jazanu.edu.sa (S.S.A.)

3 Department of Pharmacognosy, Faculty of Pharmacy, Integral University, Lucknow 226026, India; arifxyz@iul.ac.in

4 Department of Pharmaceutical Chemistry, College of Pharmacy, Prince Sattam Bin Abdulaziz University, P.O. Box 173, Al-Kharj 11942, Saudi Arabia; obaid263@gmail.com (O.A.); as.altamimi@psau.edu.sa (A.S.A.A.)

5 Department of Pharmacognosy, College of Pharmacy, Taif University, P.O. Box 11099, Taif 21944, Saudi Arabia; abuali@tu.edu.sa

6 Department of Pharmaceutical Chemistry, College of Pharmacy, Taif University, P.O. Box 11099, Taif 21944, Saudi Arabia; amrathore@tu.edu.sa

* Correspondence: drkhalid8811@gmail.com

Abstract: The fruits of Spondias mangifera (S. mangifera) have traditionally been used for the management of rheumatism in the northeast region of India. The present study explores the probable anti-arthritis and anti-inflammatory potential of S. mangifera fruit extract's ethanolic fraction (EtoH-F). To support this study, we first approached the parameters in silico by means of the active constituents of the plant (beta amyrin, beta sitosterol, oleonolic acid and co-crystallised ligands, i.e., SPD-304) via molecular docking on COX-1, COX-2 and TNF- $\alpha$. Thereafter, the absorption, distribution, metabolism, excretion and toxicity properties were also determined, and finally experimental activity was performed in vitro and in vivo. The in vitro activities of the plant extract fractions were evaluated by means of parameters like 1,1-Diphenyl-2- picrylhydrazyl (DPPH), free radical-reducing potential, albumin denaturation, and protease inhibitory activity. The in vivo activity was evaluated using parameters like COX, TNF- $\alpha$ and IL- 6 inhibition assay and arthritis score in Freund Adjuvant (CFA) models at a dose of $400 \mathrm{mg} / \mathrm{kg}$ b.w. per day of different fractions (hexane, chloroform, alcoholic). The molecular docking assay was performed on COX-1, COX-2 and TNF- $\alpha$. The results of in vitro studies showed concentration-dependent reduction in albumin denaturation, protease inhibitors and scavenging activity at $500 \mu \mathrm{g} / \mathrm{mL}$. Administration of the $S$. mangifera alcoholic fraction at the abovementioned dose resulted in a significant reduction $(p<0.01)$ in arthritis score, paw diameters, TNF- $\alpha$, IL- 6 as compared to diseased animals. The docking results showed that residues show a critical binding affinity with TNF- $\alpha$ and act as the TNF- $\alpha$ antagonist. The alcoholic fraction of $S$. mangifera extract possesses beneficial effects on rheumatoid arthritis as well as anti-inflammatory potential, and can further can be used as a possible agent for novel target-based therapies for the management of arthritis.

Keywords: arthritis; anti-inflammatory; Spondias mangifera; in silico; in vitro and in vivo

\section{Introduction}

In ancient times, traditional systems of medicine were the fundamental source of herbal medications [1]. A majority of the population is dependent the on use of various 
species of herbal remedies to treat health problems [2] because of the insufficient availability of modern medicine, particularly in rural areas [3].

Rheumatoid arthritis (RA) is an autoimmune disorder, which can result in chronic inflammation in the synovial membrane and also cause pain in small and large joints, as well as the destruction of cartilage and bone [4]. The characteristic features of RA are joint pain, immobility and malformation [5]. The management of RA is mainly achieved through the use of nonsteroidal anti-inflammatory drugs (NSAIDS) such as indomethacin, ibuprofen, aspirin, and naproxen, but these only manage it for a short time duration [6]. The arthritic and anti-inflammatory action of NSAID is attributed to it cyclooxygenase (COX-1 and 2) inhibition, as well as its inhibition of the pro cytokinins (IL1, IL-6 TNF-alpha, etc.), curing arthritic disease [7]. Some NSAID has a short duration of action and can also produce some negative side effects in the epigastric region [7]. When inflammation occurs, macrophage cells are released into the injured tissue area, which can cause lifethreatening diseases like Alzheimer's, arthritis, cancer, allergies, and atherosclerosis, as well as autoimmune diseases [1]. Inflammation causes the vasodilation of capillaries and increases the blood flow to the injured region [8].

Oxidation causes chemical and physiological changes in the biological system in living organisms and organic substances, which can be oxidised as a result of various physicochemical processes such as exposure to heat, light or any other oxidising agents [9]. Reactive oxygen species (ROS) are produced from the oxidised bioactive constituents, as a result of the direct exposure of highly reactive molecules that are abundant in living tissue to the atmosphere or during aerobic metabolism [10]. ROS circulating in the blood stream affects the metabolic process because it reacts with the free electron molecules that are present in living systems, which can lead to various life-threating diseases like ischemia, respiratory distress, arthritis, cancer, and aging, and can also damage various vital organs. Herbal medicines have numerous bioactive phytoconstituents, and have the ability to quench free radical oxygen species; this contributes beneficial effects towards life-threatening diseases in our body [11].

Spondias mangifera Willd. (Anacardiaceae), known as the bile tree, in Ayurveda system is also known as Amrata. It is widely distributed in the tropical and northeast region of India, and is cultivated in several states, but mainly in Punjab, Maharashtra, Bengal [12]. In ancient times, in the north-east region of India, people used it for the treatment of rheumatism [13]. Like various herbs, it has an odour that resembles that of turpentine upon scrubbing and/or chewing. It has numerous bioactive phytoconstituents in various parts of the plant: the fruits and aerial parts contain cycloartanone-24-methylene, daucosterol, lignoceric acid, stigmast-4-en-3-one, cystine, oleanolic acid and $\beta$-amyrin; and glycine and leucine respectively [14]. The fruits also contain some phytoconstituents like alanine, galloylgeranin, vit-A, riboflavin, and niacin in very small amounts [15].

The green fruit is useful in biliousness and dyspepsia, while the fruit powder also has anti-tubercular properties, and can also be used as an astringent, refrigerant, or tonic, and is used for the management of rheumatic arthritis and myalgia [12]. In indigenous systems of medicine, bark is used as a rubefacient on the skin over painful joints, and bark paste is used as an embrocation for both articular and muscular rheumatism [13]. In the Hazaribag district, bark paste with garlic is used in the stomach [16]. The roots are used in treatments for regulating menstruation, and possess antibacterial [17], antitumor [18], antispasmodic and antihistamine activities, and decoctions of root bark are used in the treatment of gonorrhoea. The methanolic extracts of stem heart wood possess hepatoprotective activity against carbon tetrachloride-induced liver impairment in rodents [19]. The juice of the ripe fruit of this plant is a rich source of several vitamins and can potentially be used as a nutraceutical agent [20]. The fruits and barks of the plant are also used in diabetes [21].

The present study was designed to determine the pharmacokinetics and pharmacodynamic properties of Spondias mangifera. Among all of the phytochemicals, $\beta$ sitosterol, $\beta$ amyrin and oleonolic acid are active. Bearing in mind the special considerations for determining the anti-inflammatory and anti-arthritic actions of the plant, first, the active 
constituents were tested in a docking study to determine the binding affinity, and then they were further tested in a pharmacokinetics study. Finally, the ethanolic fraction of the plant extract was used for the estimation of pharmacological activity against inflammation and CFA-induced arthritis in an animal model.

\section{Materials and Methods}

\subsection{Plant Collection and Authentication}

Crude fruits of the plant were collected from the local market in Aminabad, Lucknow India. The fruits were identified by the taxonomist at the Department of Pharmacognosy, faculty of Pharmacy, Integral University, Lucknow. A voucher sample was submitted to the herbarium for supplementary reference (IU/PHAR/HRB/20/16).

\subsection{Chemicals}

Ascorbic acid, ferrous sulphate, aluminium chloride, sulphanilamide, phosphoric acid, naphthylene diamine dihydrochloride, and rutin were bought from Qualigens Fine Chemicals, Mumbai, India. DPPH and folin ciocalteu reagents were purchased from SigmaAldrich, St. Louis, USA. Sodium carbonate, gallic acid and trypsin were attained from Merck Chemicals (Darmstadt, Germany). Tris-HCl buffer, Ferrous ammonium sulphate, and sodium dodecyl sulphate (Qualigens Fine Chemicals, Mumbai, India). All the reagents used in the experiment were of analytical grade.

\subsection{Molecular Docking}

Glide 5.9, executed in Maestro 9.4 (GUI of Schrodinger), was used for extra-precision (XP) docking of $\beta$-amyrin, $\beta$-sitosterol, oleonolic acid and co-crystallised ligands. The $X$-ray crystal structures of COX-1 (PDB ID: 3N8Z, resolution: $2.90 \AA$ ), COX-2 (PDB ID: 4PH9, resolution: $1.81 \AA$ ), and TNF- $\alpha$ (PDB ID: $2 \mathrm{AZ}$, resolution: $2.10 \AA$ ) were obtained from Protein Data Bank (PDB) and used for in silico study [22-24]. Protein Preparation Wizard in Maestro was employed for the protein structure preparation, viz., omission of water particles, required bond orders, enclosure of hydrogen atoms, and treatment of formal charges. A comprehensive sampling option was employed for the optimisation of the hydrogen bonding grid. The energy of the protein structures was minimised to an RMSD of $0.3 \AA$ using the impref module (Impact 5.9) with the OPLS_2005 force field. Glide scoring grids (docking grid box of $20 \times 20 \times 20 \AA$ ) were produced using the active binding site residues in the protein structure. LigPrep 2.6 and Epik 2.4 were used to expand protonation, as well as tautomeric states of $\beta$-amyrin, $\beta$-sitosterol, oleonolic acid and co-crystallised ligands at $\mathrm{pH} 7.0 \pm 2.0$, and then the energy was decreased by means of the OPLS_2005 force field. The docking simulation of the set ligands was performed by means of Glide XP docking [25].

2.4. Prediction of Swiss Absorption, Distribution, Metabolism, Excretion and Toxicity Properties (ADME/Tox) of the phytoconstituents from Spondias mangifera

Prediction of ADME properties was carried out using Swiss ADME software from the Swiss Institute of Bioinformatics, accessed via a web server that displays the submission page of the Swiss ADME for estimating the individual ADME behaviours of the prominent compounds of S. mangifera (gallic acid, kaempferol, quercetin and ascorbic acid). The list was constructed such that it contained one input molecule per line with several inputs, defined by a simplified molecular input line entry system, and the results for each molecule were presented in the form of tables, graphs and an excel spreadsheet. The significant ADME properties predict both physicochemically significant descriptors and pharmacokinetically relevant properties. ADME properties determine the drug-like activity of ligand molecules on the basis of Lipinski's rule of five. In this study, they were used to measure the safety of the compounds present in the plant S. mangifera [26]. 


\subsection{Extract and Fraction Preparation}

The $S$. mangifera fruits were collected and dried; for the drying process, they were scattered on a dry open area at room temperature. After air drying, the fruits were cut into four pieces by the means of a sharp knife. In addition, they were again dried in an oven at $40-45^{\circ} \mathrm{C}$ for a period of 2-3 days until constant weight. The dried fruits were made into coarse powder using a grinder, and the powder materials were defatted with petroleum ether and further macerated with methanol for $72 \mathrm{~h}$ with occasional shaking. The extract was filtered with Whatmann filter paper three times at intervals of one day the extract was kept on a rotatory evaporator at low temperature to obtain a viscous and sticky mass of the extract.

The filtrate was fractionated through the solvent according to ascending order of polarity, as follows: hexane < chloroform < ethanol respectively. Each fraction was concentrated up to dryness at $40^{\circ} \mathrm{C}$ by using a rotary evaporator. The dried fractionated extract was then kept at $4{ }^{\circ} \mathrm{C}$ until further use [11].

\subsection{Animals}

Albino swiss mice (both sexes) of equal weight (35 g) were purchased from the National Laboratory Animal centre, Central Drug Research Institute, Lucknow, Uttar Pradesh, India (Approval No.: IU/CPCSEA/08/ac/1213). The necessary approval from the Institutional Ethical Committee was obtained, and fresh and healthy animals were selected. No experimental study was conducted. The animals were housed separately in polypropylene cages at a temperature of $21+2{ }^{\circ} \mathrm{C}$ and relative humidity $(55 \pm 5 \%)$, with a light/dark cyclic of 12-h, for one week and fed with pellets and water ad libitum.

\subsection{COX Inhibition Assay}

This test was performed as per the Viji and Helen assay. According to the given protocol, a mixture was prepared using tris- $\mathrm{HCl}$ buffer enzyme, haemoglobin, glutathione, arachidonic acid and Trichloroacetic acid (TCA; $10 \%$ in $1 \mathrm{~N} \mathrm{HCl}, 0.2 \mathrm{~mL}$ ). This mixture was then incubated for approximately $20 \mathrm{~min}$ at $37^{\circ} \mathrm{C}$. Thereafter, $0.2 \mathrm{~mL}$ of thiobarbituric acid (TBA reagent) was added to the mixture, which was subsequently kept on boiling water for $20 \mathrm{~min}$. Afterward, it was cooled and centrifuged at $1000 \mathrm{rpm}$ for $3 \mathrm{~min}$. The final supernatant was used for the measurement of COX activity at $560 \mathrm{~nm}$ [27].

$$
\text { COX inhibition activity }(\%)=1-\mathrm{T} / \mathrm{C} \times 100
$$

$\mathrm{T}$ is the absorbance of the inhibitor well (at $560 \mathrm{~nm}$ ) and $\mathrm{C}$ denotes the initial absorbance activity without the inhibitor well (at $560 \mathrm{~nm}$ ).

\subsection{TNF- $\alpha$ and IL-6 Inhibition Assay}

The Tumour Necrosis Factor alpha (TNF- $\alpha$ ) inhibitory assay of the $S$. mangifera fractions was performed using an ELISA kit (Thermo Scientific, Waltham, USA) for quantification of TNF- $\alpha$ and IL- 6 in the experimental rats' serum. In accordance with the instruction leaflet, absorbance was measured at 450 and $550 \mathrm{~nm}$ on an ELISA plate reader.

\subsection{1,1-diphenyl-2-Picrylhydrazyl Scavenging Assay}

Different fractions of $S$. mangifera were analysed using the method provided in Liyana and Shahidi, with slight modification. DPPH $(0.135 \mathrm{mM})$ solution was mixed in $1 \mathrm{ml}$ of ethanol and kept on vortex to mix thoroughly. The reaction mixture was incubated at a temperature of $25{ }^{\circ} \mathrm{C}$ for a time period of approximately $15-20 \mathrm{~min}$, and then further absorbance was recorded at $490 \mathrm{~nm}$. The scavenging activity of DPPH was calculated as per the formula below [28].

$$
\% \text { Inhibition }=[(\mathrm{A} 0-\mathrm{A} 1) / \mathrm{A} 0 \times 100]
$$


where A0 is the absorbance of the blank, whereas A1 is the absorbance of the extract fraction sample.

\subsection{Reducing Potential Scavenging Activity}

According to the Khalid et al. method, the transformation of $\mathrm{Fe}^{+3}$ to $\mathrm{Fe}^{+2}$ in the presence of the fractions was measured at an absorbance of $700 \mathrm{~nm}$ after adding the regents. Increased absorbance of the reaction mixture indicates increased reducing power. Gallic acid was used as standard [29].

\subsection{Inhibition of Albumin Denaturation}

Egg albumin $(0.2 \mathrm{~mL})$ was added in all the fractionated extracts; to these mixtures, phosphate-buffered saline ( $2.8 \mathrm{~mL}$; $\mathrm{pH} 6.4$ ) was added. The final volumes of the samples were then made up with distilled water up to $5 \mathrm{~mL}$. For control purposes, double-distilled water and aspirin were used as standard. The fractionated extracts were incubated in a biological oxygen demand chamber at $37^{\circ} \mathrm{C}$ for $15 \mathrm{~min}$, following which the mixtures were heated at $70{ }^{\circ} \mathrm{C}$ for no longer than $5 \mathrm{~min}$. Then, these mixtures were cooled, and the absorbance was measured at $660 \mathrm{~nm}$ [30].

The formula for the calculation of percentage inhibition of protein denaturation is mentioned below:

$$
\text { Percentage Inhibition }=\frac{\text { Abs control }- \text { Abs treated } \times 100}{\text { Abs treated }}
$$

\subsection{Protease Inhibition Assay}

This procedure was performed as per the protocol of Dharmalingam and group, with a slight modification. For this, $2 \mathrm{~mL}$ of reaction mixture consisting of trypsin $(0.06 \mathrm{~mL})$, Tris $\mathrm{HCl}$ buffer $(1 \mathrm{~mL} ; 20 \mathrm{mM}$; $\mathrm{pH} 7.4)$ and fractionated extracts of the plant $(1 \mathrm{~mL})$ was incubated for $10 \mathrm{~min}$ at $37^{\circ} \mathrm{C}$. Afterward, casein $(1 \mathrm{~mL}$ of $0.65 \% \mathrm{w} / \mathrm{v})$ was added, and the mixture was further re-incubated for $20 \mathrm{~min}$. Subsequently Perchloric acid (2 mL; $2 \mathrm{M})$ was added to that mixture, a cloudy suspension was obtained and centrifuged at $7830 \mathrm{rpm}$ for $20 \mathrm{~min}$. The absorbance of the supernatant liquid was measured at $280 \mathrm{~nm}$. Tris- $\mathrm{HCl}$ buffer solution was used as a control. The formula that was used for the calculation of $\%$ inhibition is mentioned below [31].

$$
\% \text { inhibition }=(1-\mathrm{Ac} / \mathrm{At}) 100
$$

In this Ac denotes the absorbance of control sample whereas at shows the absorbance related with test sample.

\subsection{Complete Freund's Adjuvant (CFA)-Induced Arthritis in Rats}

The arthritis model was performed in pathogen-free experimental rats by the plantar injection of $0.1 \mathrm{~mL}$ of CFA on day 0 . The experimental rats were randomly divided into six groups. Group I served for the normal control (vehicle). Group II and III were CFA and CFA plus Aspirin (100 mg/kg per day p.o.), respectively. Group IV was the treated group of CFA plus hexane extracted fraction (Hx-F; $400 \mathrm{mg} / \mathrm{kg}$ per day p.o.). Group V served as CFA plus chloroform extracted fraction (Chl-F; $400 \mathrm{mg} / \mathrm{kg}$ per day p.o.). Group VI served as the treated CFA group plus ethanol extracted fraction (EtOH-F; $400 \mathrm{mg} / \mathrm{kg}$ per day p.o.). The experiment was performed for 40 days with the respective groups of animals. Animals were examined carefully throughout the experiments [32].

\subsection{Arthritic Score}

The degree and score of arthritis was monitored daily by means of a scale from 0 to 4 for each paw, aiming for a maximum score of 8 per rat. After induction of arthritis, the joint diameters of the right hind paw were measured using an electronic Vernier calliper (Fischer Scientific, CON3417) [33]. 
The scoring criteria are mentioned below:

Normal paw $=0$,

Mild swelling and erythema of digits $=1$,

Swelling and erythema of the digits $=2$,

Severe swelling and erythema $=3$,

Gross deformity and inability to use the limb $=4$.

\subsection{Statistical Analysis}

The results are expressed as mean \pm SEM of six animals per group. Statistical significance was calculated by means of ANOVA (Graph Pad Software Inc., San Diego, USA), followed by Dunnet " $t$ " test, and $p<0.05$ was considered statistically significant.

\section{Results}

To the best of our knowledge, this is the first study that includes pharmacokinetics, dynamics, in silico, in vitro and in vivo studies on the extract fraction of the plant Spondias mangifera. This shows the probable anti-inflammatory and anti-arthritic action of the plant. The outcomes of the results can be proved with respect to several aspects, described below.

\subsection{Molecular Docking}

The major constituents beta amyrin, beta sitosterol, and oleanolic acid were docked into the active site of COX-1(PDB ID: 3N8Z, resolution: $2.90 \AA$ ), COX-2 (PDB ID: 4PH9, resolution: $1.81 \AA$ ), and TNF- $\alpha$ (PDB ID: 2AZ5, resolution: $2.10 \AA$ ) using Glide XP docking via the Maestro GUI of Schrodinger. None of the compounds showed any binding affinity with COX-1 and COX-2. The major constituents $\beta$-amyrin, $\beta$-sitosterol, and oleonolic acid showed excellent binding affinity with pro-inflammatory cytokine TNF- $\alpha$. The cocrystallised ligand SPD-304 showed a similar binding pose to that in the crystal structure, validating our docking protocol. The summary of the Glide XP score and interacting binding residues is provided in Table 1. The 2D and 3D illustrations of the binding pose of beta amyrin, beta sitosterol, oleonolic acid and SPD-304 at the interface of chain A and B of TNF- $\alpha$ are presented in Figures 1 and 2, respectively.

Table 1. Summary of the selected constituents and the reference compound (SPD-304); chemical structures, Glide XP docking scores, hydrogen bond interactions and close contact residues.

\begin{tabular}{|c|c|c|c|c|}
\hline Ligands & Chemical Structure & $\begin{array}{l}\text { Binding Energy } \\
\text { Score (Kcal/Mol) }\end{array}$ & $\begin{array}{l}\text { Interaction } \\
\text { (H-Bond) }\end{array}$ & Interaction (Hydrophobic) \\
\hline SPD-304 & & -8.137 & Gly A: 121 & $\begin{array}{c}\text { Leu A: } 57, \text { Tyr B: 59, Tyr B: 119, } \\
\text { Gly B: } 121, \text { Tyr B: } 151\end{array}$ \\
\hline$\beta$-amyrin & & -7.517 & - & $\begin{array}{c}\text { Leu A: 57, Tyr A: 59, Tyr A: } 119 \text {, } \\
\text { Ile A: } 155, \text { Leu B: } 57, \text { Tyr B: } 59 \text {, } \\
\text { Tyr B: } 119, \text { Tyr B: } 151\end{array}$ \\
\hline
\end{tabular}


Table 1. Cont.

\begin{tabular}{|c|c|c|c|c|}
\hline Ligands & Chemical Structure & $\begin{array}{l}\text { Binding Energy } \\
\text { Score (Kcal/Mol) }\end{array}$ & $\begin{array}{l}\text { Interaction } \\
\text { (H-Bond) }\end{array}$ & Interaction (Hydrophobic) \\
\hline$\beta$-sitosterol & & -9.190 & Gln A: 61 & $\begin{array}{c}\text { Leu A: 57, Tyr A: 59, Tyr A: 119, } \\
\text { Leu B: 57, Tyr B: 59, Tyr B: 119, } \\
\text { Tyr B: } 151\end{array}$ \\
\hline $\begin{array}{l}\text { Oleonolic } \\
\text { acid }\end{array}$ & & -8.178 & $\begin{array}{l}\text { Gly A: } 121 \\
\text { Tyr B: } 151\end{array}$ & $\begin{array}{c}\text { Leu A: } 57, \text { Tyr A: } 59 \text {, Tyr A: } 119 \text {, } \\
\text { Ile A: } 155 \text {, Leu B: } 57 \text {, Tyr B: 59, } \\
\text { Tyr B: } 119\end{array}$ \\
\hline
\end{tabular}

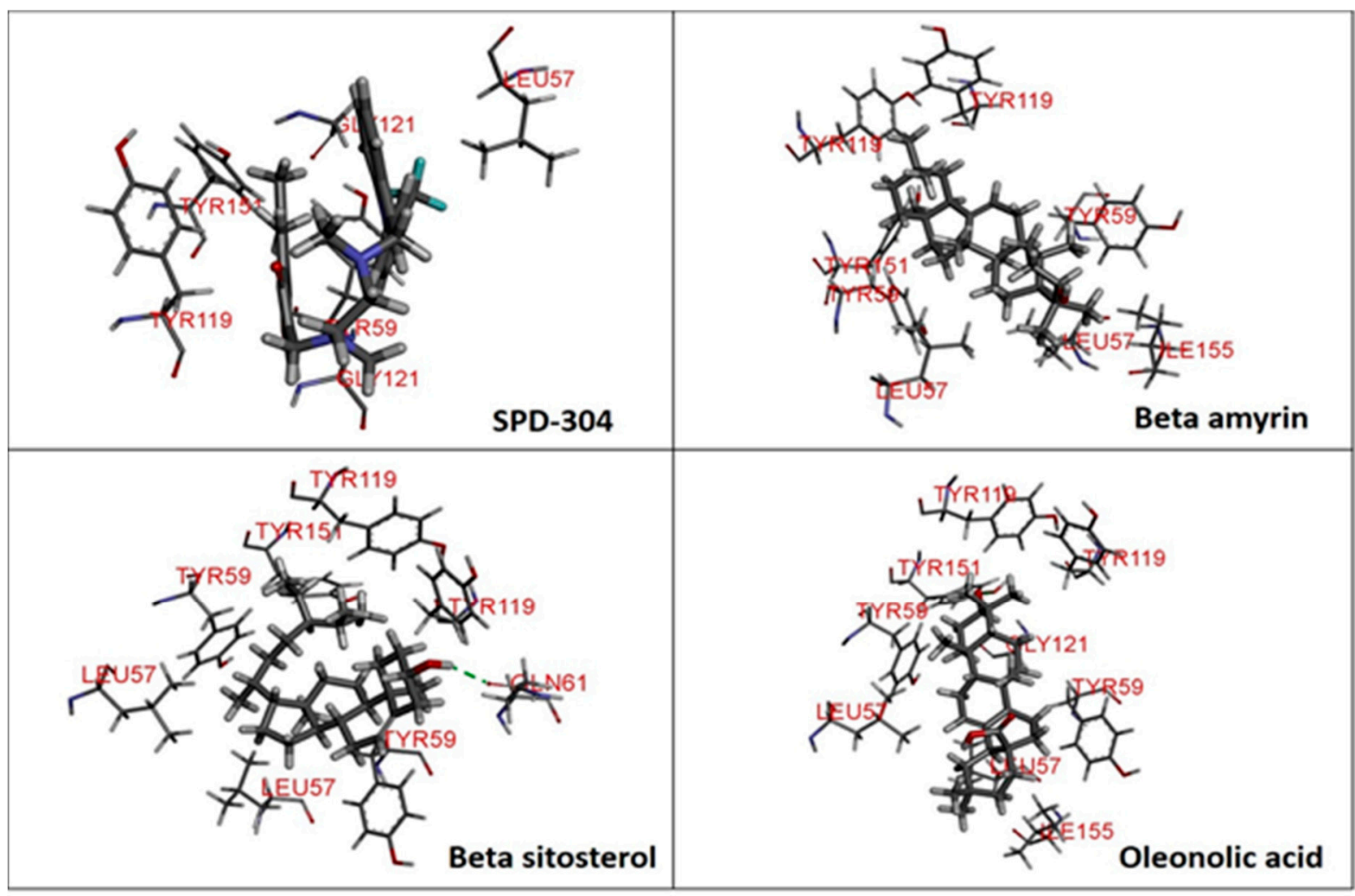

Figure 1. 2D representation of docked conformation of TNF- $\alpha$ with ligands obtained after glide XP docking. Green dashed lines represent conventional hydrogen bonds with the interacting amino acid residues. Pink lines indicate hydrophobic (alkyl-alkyl, $\pi$-alkyl or $\pi-\pi$ ) interactions. 


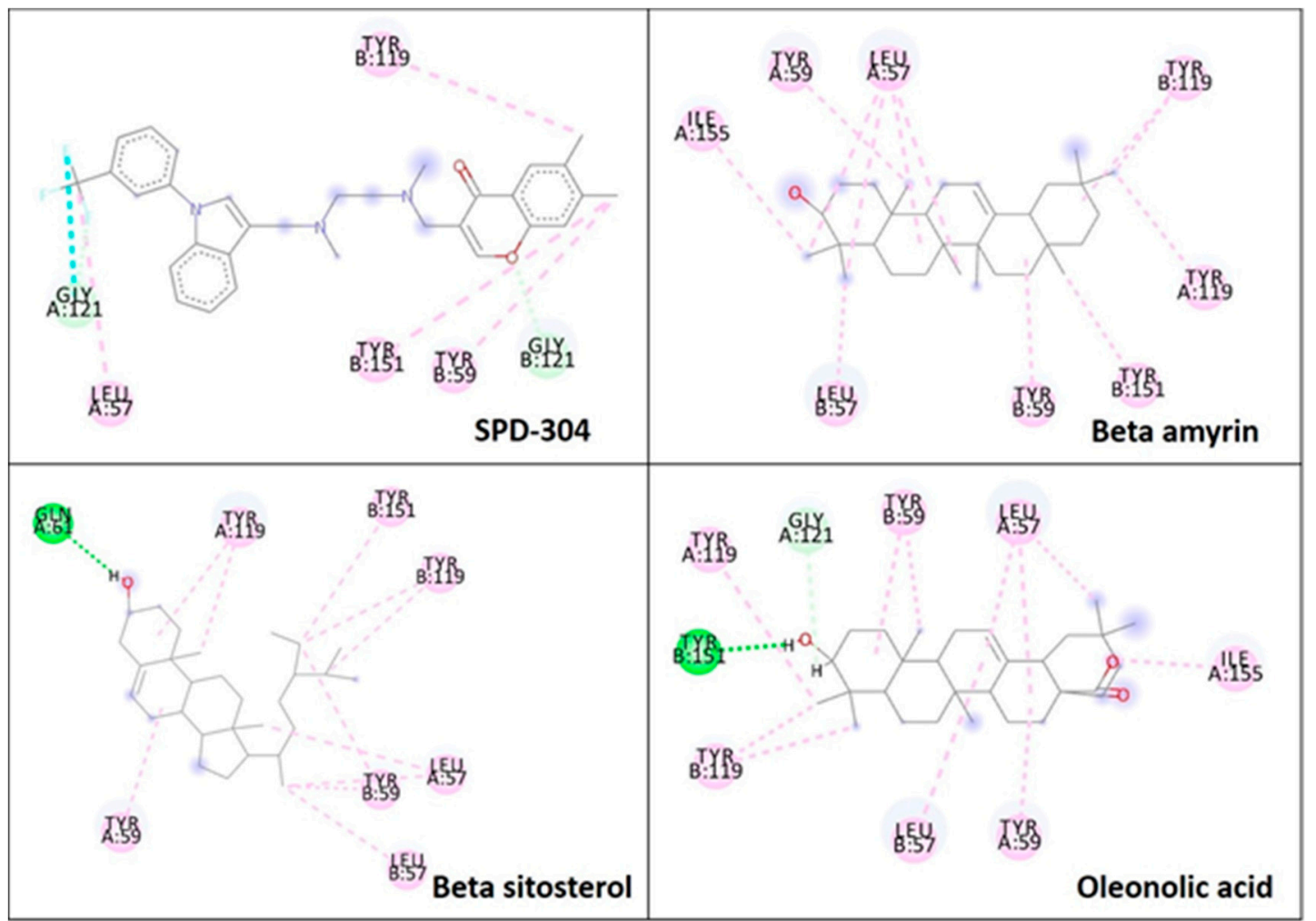

Figure 2. 3D representation of docked conformation of TNF- $\alpha$ with ligands obtained after Glide XP docking.

\subsection{Server-Based ADME Analysis}

Server-based ADME analysis provides rapid results, which can be useful for the development of lead compounds. In our study, we used Swissdock for the ADME analysis of selected molecules from the literature. The results of ADME analysis are described in Table 2 and the docking figure is shown in Figure 3. The predicted properties of kaempferol, gallic acid, quercetin and ascorbic acid are within ranges satisfying all of the stipulations of Lipinski's rule of five for consideration as having drug-like potential. Figure 3 clearly shows that there are no compounds that cross the blood-brain barrier. Among these compounds, compound gallic acid and caffeic show the best ADME properties.

Table 2. Pharmacokinetic parameters of phytoconstituents of S. mangifera fruits.

\begin{tabular}{ccccccc}
\hline Molecule & MW & Ali Class & GI Absorption & BBB Permeant & Log Kp (cm/s) & $\begin{array}{c}\text { Lipinski } \\
\text { \#Violations }\end{array}$ \\
\hline Gallic acid & 170.12 & Soluble & High & No & -6.84 & 0 \\
\hline Kaempferol & 286.24 & Soluble & High & No & -6.70 & 0 \\
\hline Quercetin & 302.24 & Soluble & High & No & -7.05 & 0 \\
\hline Ascorbic acid & 176.12 & Very soluble & High & No & -8.54 & 0 \\
\hline
\end{tabular}




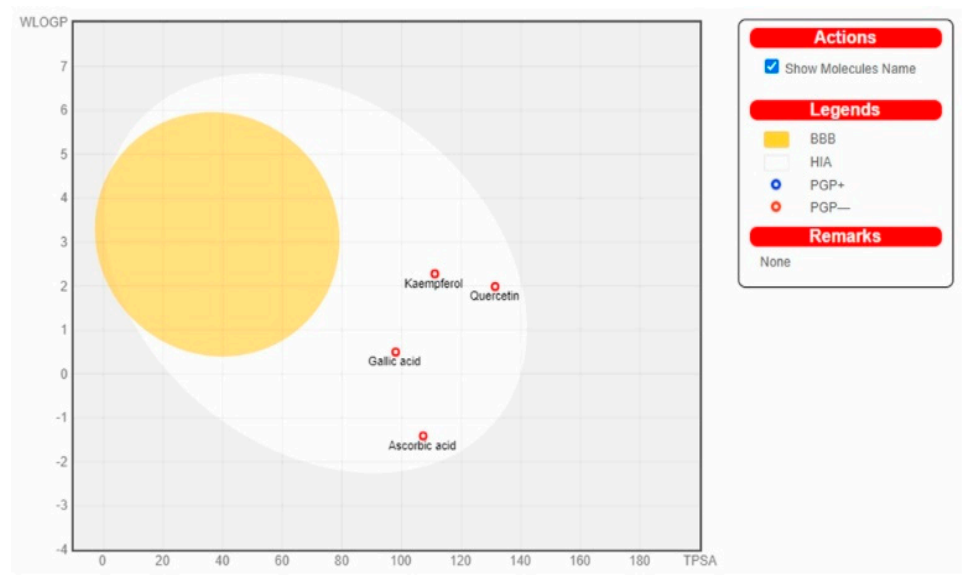

Figure 3. The figure shows that no compounds cross blood-brain barrier. Among these compounds, the compounds gallic acid and caffeic exhibit the best ADME properties.

\subsection{Cyclooxygenase Assay}

The COX-1 and COX-2 inhibition effect was investigated using different fractions of S. mangifera extract. None of the fractions of $S$. mangifera extract, i.e., hexane, chloroform, ethanol fractions, showed a percentage inhibition of cyclooxygenase (COX 1 and 2) activity. This means that the test fractions and reagents did not react with each other. Therefore, the results for this are not included.

\subsection{TNF-Alpha}

This study revealed that TNF- $\alpha$ plays a significant role in the inflammatory process. The highest concentration of TNF- $\alpha$ resulted in a significant $(p<0.01)$ improvement in the toxic control compared to the normal group. When the ethanolic fraction of S. mangifera was orally administered at a dose of $400 \mathrm{mg} / \mathrm{kg}$ per day, the concentration of TNF- $\alpha$ showed a significant $(p<0.05)$ reduction $(71.83 \pm 2.71)$, whereas the other fractions, like Hx-F (131.72 \pm 4.91$)$ and Chl-F (89.51 \pm 3.21$)$, did not show a significant $(p>0.05)$ effect on TNF- $\alpha$ concentration when compared with the toxic control group at this dose. Group III shows significantly reduced the concentration of TNF - $\alpha$ when compared with group II $(68.51 \pm 2.98)$. (Figure 4$)$. The evaluated concentration of IL-6 was significantly $(p<0.01)$ increased in the group II animals compared to those in group I. Group III shows significantly reduced the concentration of IL - 6 when compared with group II $(61.51 \pm 2.17)$. When the alcoholic fraction of $S$. mangifera extract was administered at a dose of $400 \mathrm{mg} / \mathrm{kg}$ in the Group VI animals, the results showed a significant $(p<0.05)$ reduction $(68.83 \pm 1.87)$ in the IL- 6 concentration, whereas there was no reduction in the IL- 6 concentration in groups IV and V (121.72 \pm 3.71 and $76.51 \pm 2.81$, respectively) when compared to the group II animals (Figure 5). 


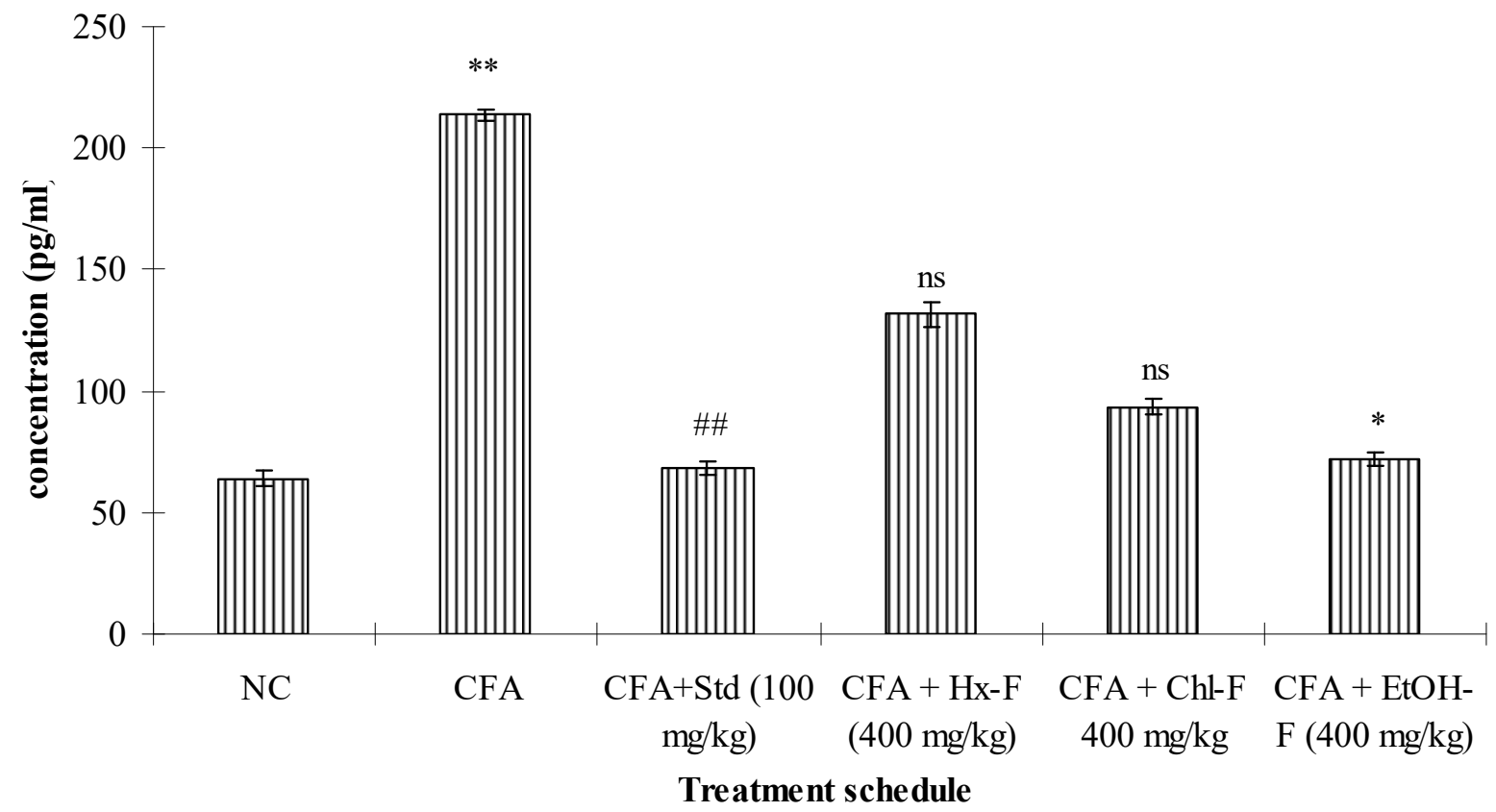

Figure 4. Effect of $S$. mangifera ethanolic fraction on TNF- $\alpha$. Results are expressed as mean \pm SEM $(n=6)$ and analysed by one-way ANOVA followed by Dunnet's test. ${ }^{* *} p<0.01=$ significant when compared with group I. ${ }^{\# \#} p<0.01,{ }^{*} p<0.05=$ significant when compared with group II. ${ }^{\text {ns }} p>0.05=$ non-significant when compared with group II.

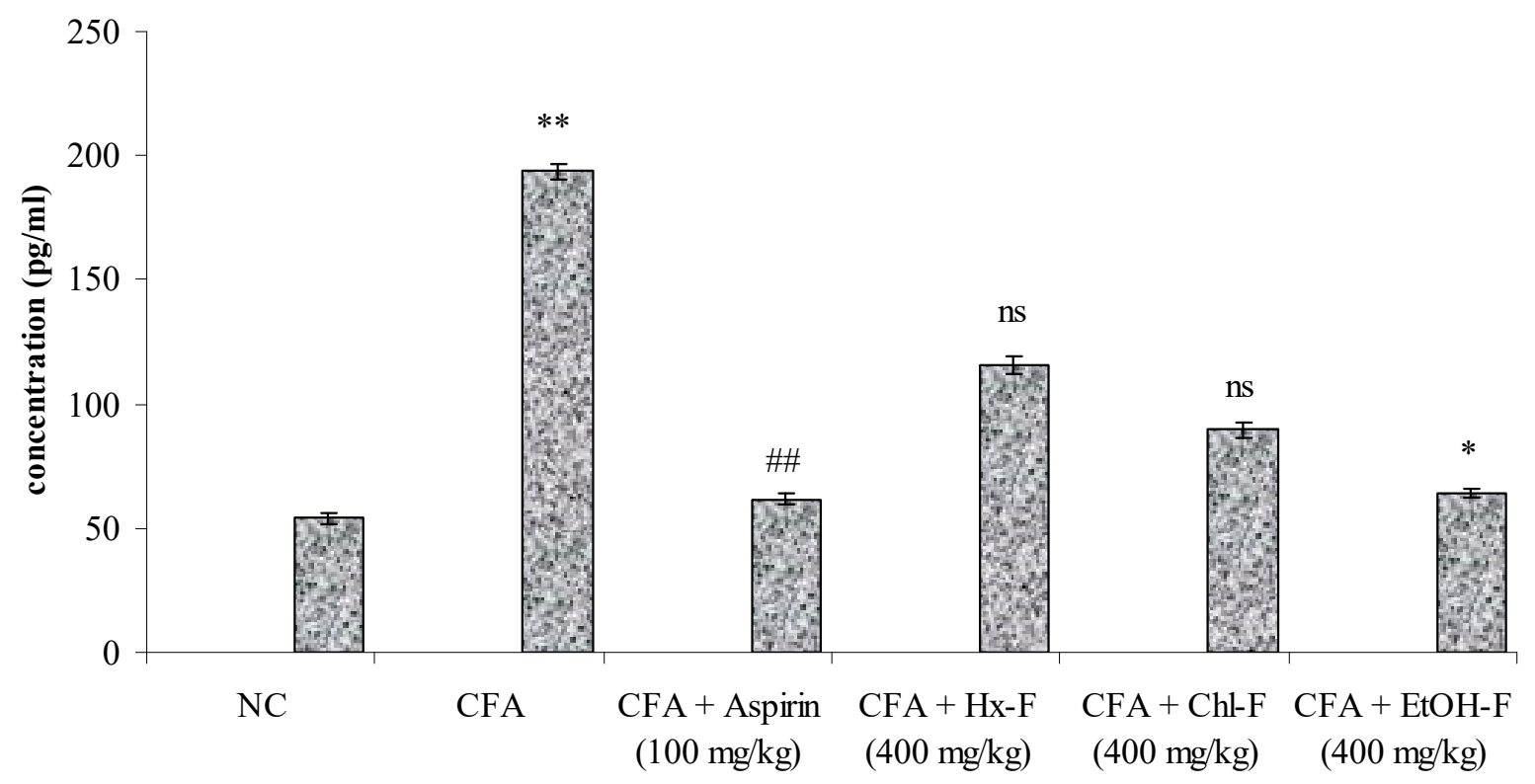

Treatment schedule

Figure 5. Effect of S. mangifera ethanolic fraction on IL-6. Results are expressed as mean \pm SEM $(n=6)$ and analysed by one-way ANOVA followed by Dunnet's test. ${ }^{* *} p<0.01=$ significant when compared with group I. ${ }^{\#} p<0.01,{ }^{*} p<0.05=$ significant when compared with group II. ${ }^{\text {ns }} p>0.05=$ non-significant when compared with group II.

\subsection{DPPH Scavenging Activity}

This study showed that the ethanolic fraction of S. mangifera has greater scavenging activity than the other fractions (hexane, chloroform, and ethanol) in comparison to the standard (ascorbic acid). It significantly showed a maximum percentage inhibition of $87.01 \pm 2.73 \mathrm{mg} / \mathrm{mL}$, while ascorbic acid was $101.72 \pm 3.17$, at a dose of $1.5 \mathrm{mg} / \mathrm{mL}$; the hexane and chloroform fraction were $57.98 \pm 1.97$ and $71.37 \pm 1.87$, respectively, at this dose (Figure 6). 


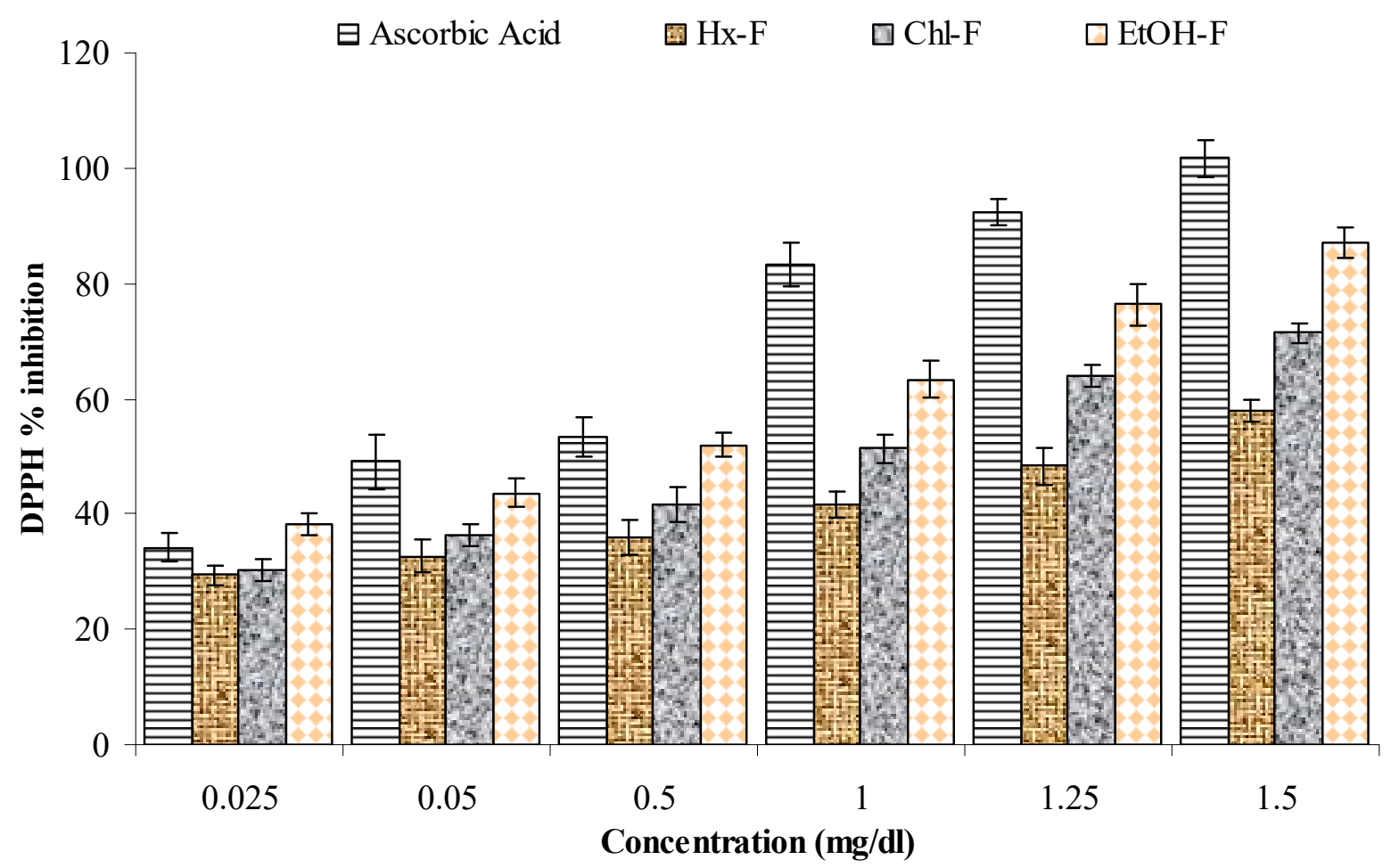

Figure 6. Percentage inhibition of DPPH scavenging activity of $S$. mangifera fruit fractions. Data are presented as the mean value $\pm \operatorname{SEM}(n=3)$.

\subsection{Reducing Potential}

In Figure 7 , it is revealed that the highest absorbance of the $S$. mangifera fractions was found for the ethanolic fraction $(0.793 \pm 0.03 \mathrm{~nm})$ at $140 \mathrm{mg} / \mathrm{mL}$, whereas the values for the hexane and chloroform fractions were $0.493 \pm 0.05 \mathrm{~nm}$ and $0.598 \pm 0.05 \mathrm{~nm}$, respectively, at a concentration of $140 \mathrm{mg} / \mathrm{mL}$.

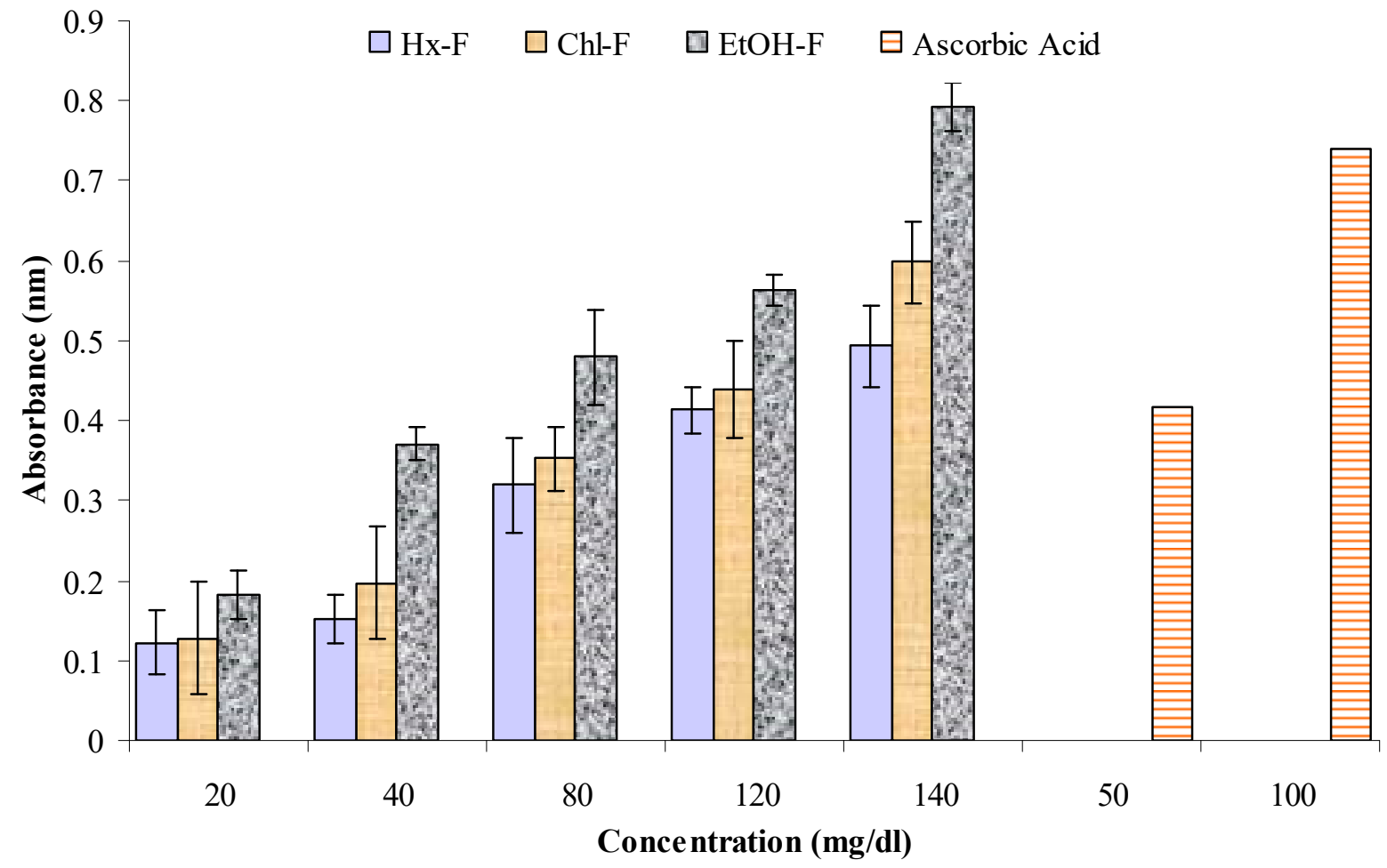

Figure 7. Reduced potential scavenging activity of different fractions of S. mangifera fruit extract. 


\subsection{Albumin Denaturation}

The ethanolic fraction of S. mangifera significantly $(p<0.05)$ showed the greatest antidenaturation effect for protein $(89.57 \pm 1.49 \mu \mathrm{g} / \mathrm{mL})$, whereas the hexane and chloroform fractions had values of $57.61 \pm 1.93$ and $67.31 \pm 1.39$, respectively, when compared with acetylsalicylic acid $(98.76 \pm 1.93 \mu \mathrm{g} / \mathrm{mL}$ ) at a concentration of $500 \mu \mathrm{g} / \mathrm{mL}$ (Figure 8).

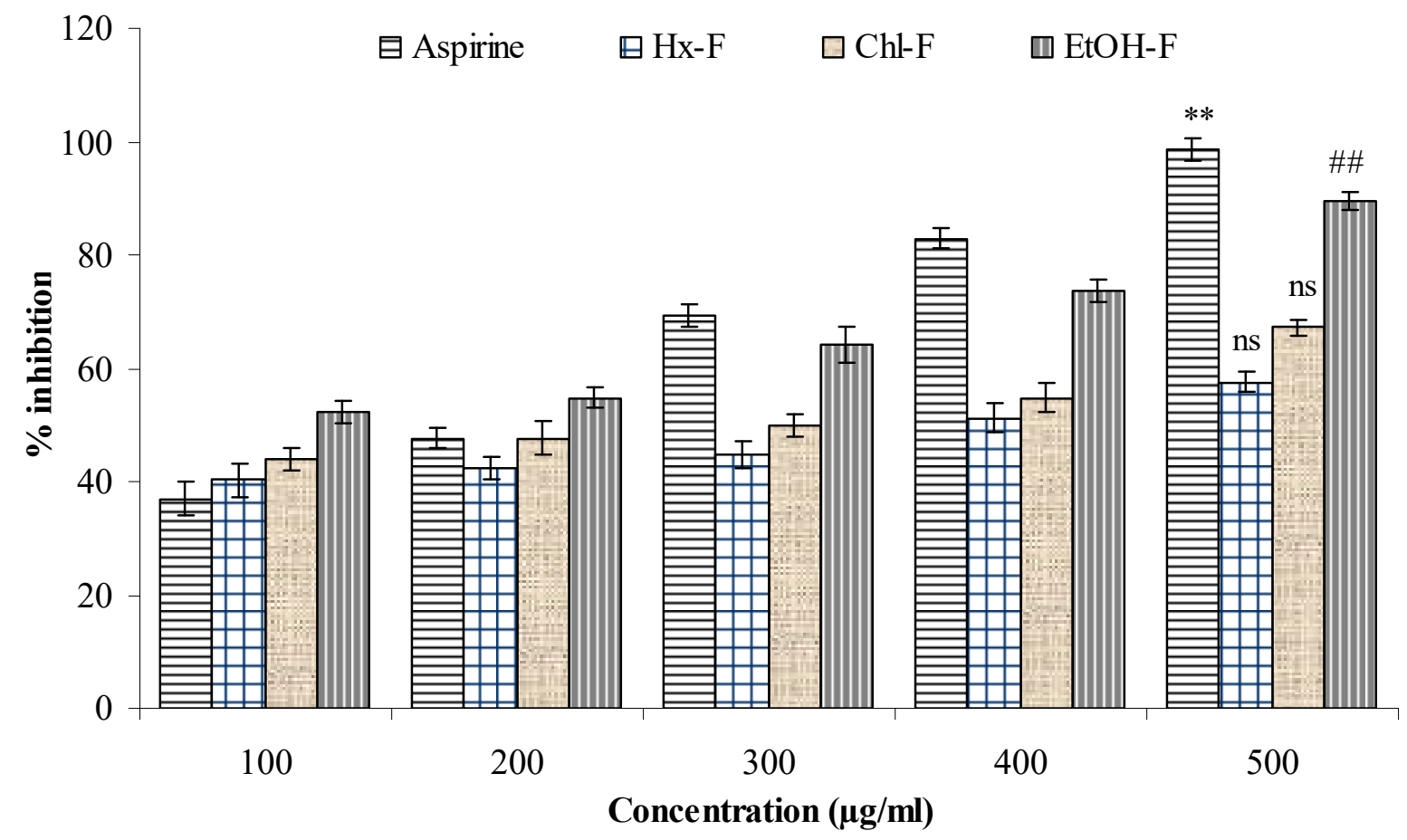

Figure 8. Effect of $S$. mangifera ethanolic fraction against protein denaturation using egg albumin. Data are expressed as means $\pm \operatorname{SEM}(n=3)$, with a significance test for comparison with aspirin using ANOVA followed by Dunnet's ' $t$ ' test. ${ }^{* *} p<0.01,{ }^{\# \#} p<0.05$ and ${ }^{\text {ns }} p>0.05$ : non-significant.

\subsection{Protease Inhibitor}

A significant proteinase inhibitory efficacy $(p<0.05)$ was shown for the ethanolic fraction of $S$. mangifera $(81.49 \pm 2.14 \mu \mathrm{g} / \mathrm{mL})$, whereas the hexane and chloroform fractions had values of $63.59 \pm 1.97 \mu \mathrm{g} / \mathrm{mL}$ and $71.31 \pm 1.49 \mu \mathrm{g} / \mathrm{mL}$, respectively, and did not show significant $(p>0.05)$ action when compared with acetylsalicylic acid $(98.76 \pm 1.93)$ at a concentration of $500 \mu \mathrm{g} / \mathrm{mL}$ (Figure 9). 


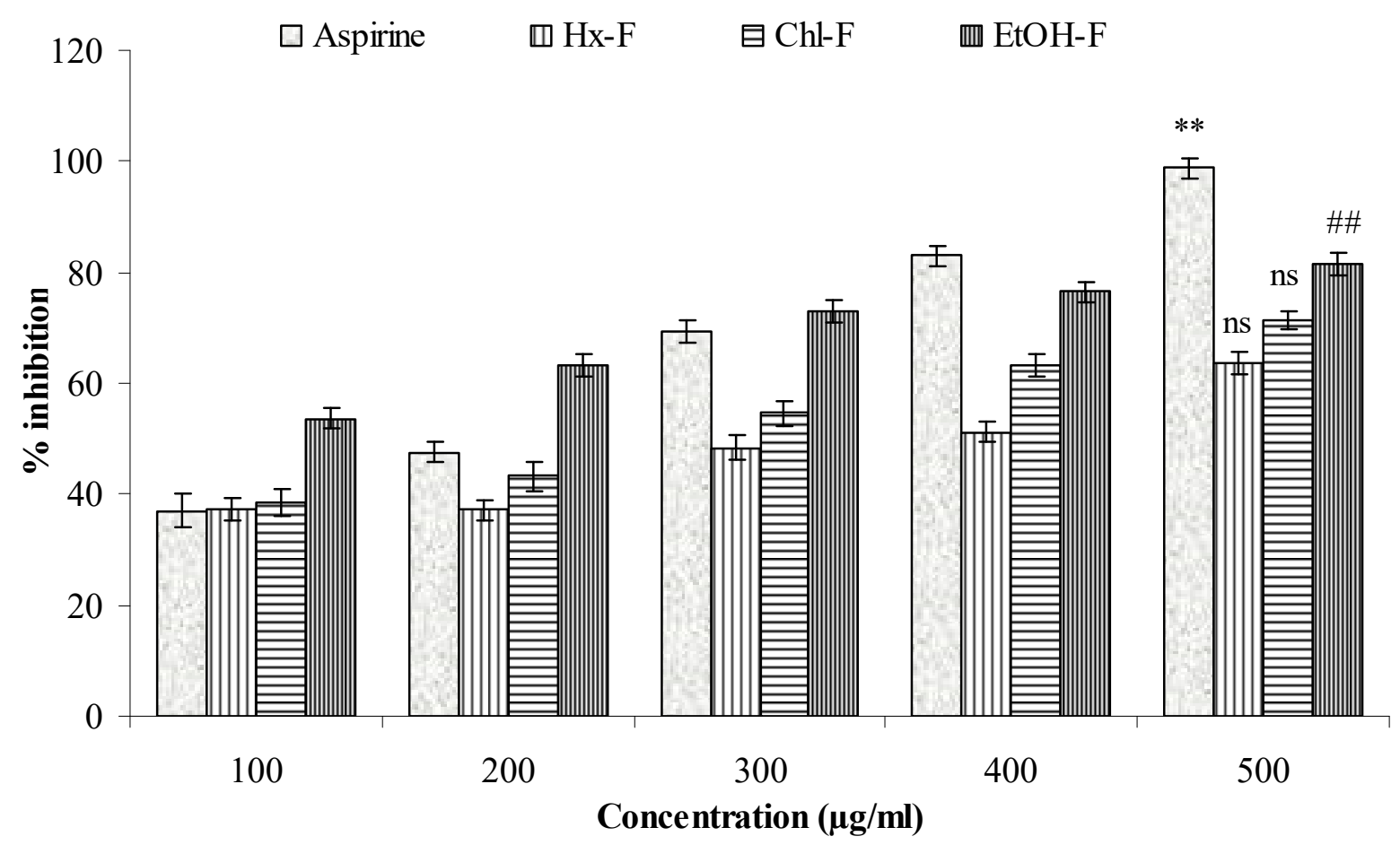

Figure 9. Effect of $S$. mangifera ethanolic fraction against protein denaturation using egg albumin. Data are expressed as means $\pm \operatorname{SEM}(n=3)$, with a significance test for comparison with aspirin using ANOVA followed by Dunnet's ' $t$ ' test. ${ }^{* *} p<0.01,{ }^{\# \#} p<0.5$ and ${ }^{\text {ns }} p>0.05$ : non-significant.

\subsection{Anti-Arthritic Potential of S. mangifera against CFA-Induced Arthritis}

When the CFA injected into the positive control group II, the animals' paw diameter increased significantly $(p<0.01)$ from day 3 to day 28 when compared with the normal group animals. However, the percentage inhibition of the $S$. mangifera fraction at a dose of $400 \mathrm{mg} / \mathrm{kg}$ per day in the group VI animals was significantly $(p<0.05)$ decreased $(83.84 \%)$ when compared with the positive control group II animals. Meanwhile, the percentage inhibition of the Hx-F and Chl-F fractions did not show a significant $(p>0.5)$ effect (53.07 and 60.74, respectively) on paw diameter when compared with the group II animals at this dose. However, the group III animals administered $100 \mathrm{mg} / \mathrm{kg}$ aspirin (standard) exhibited significantly $(p<0.01)$ reduced anti-arthritic potential $(1.22 \pm 1.16 ; p<0.01)$ (Figure 10). 


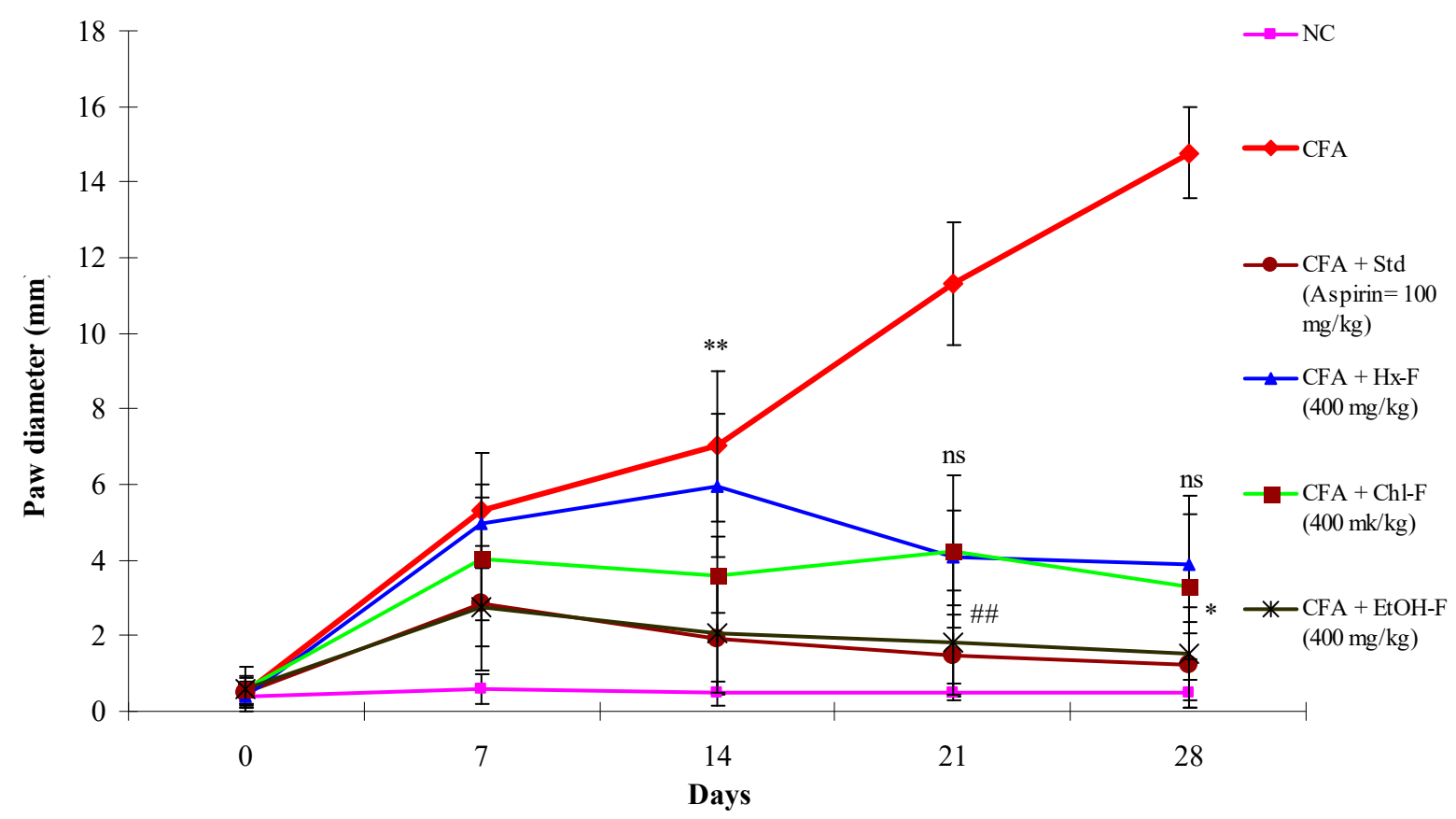

Figure 10. Effects of $S$. mangifera ethanolic fraction on CFA-induced arthritis in mice. All values are expressed as Mean = $\operatorname{SEM}(n=6) .{ }^{* *} p<0.01=$ significant when compared with group I. ${ }^{\#} p<0.01$ and ${ }^{*} p<0.05=$ significant when compared with group II. ns $p>0.05$ : non-significant when compared with group II.

\subsection{Arthritis Index}

This study revealed a continuous and significant $(p<0.01)$ increase in the arthritic score in the group II animals compared to the group I animals. When the S. mangifera extract fraction was orally administered at a dose of $400 \mathrm{mg} / \mathrm{kg}$; the group VI animals exhibited a significantly $(p<0.05)$ reduced $(0.7 \pm 0.27)$ arthritic score when compared with the group II animals, whereas the group IV and V animals did not show a significantly $(p>0.01)$ reduced (1.7 $\pm 0.111 .6 \pm 0.63)$ arthritis score. However, the group III animals administered $100 \mathrm{mg} / \mathrm{kg}$ aspirin (standard) exhibited significantly $(p<0.01)$ reduced $(0.6 \pm 0.18)$ arthritis score, similar to the group II animals (Figure 11). 


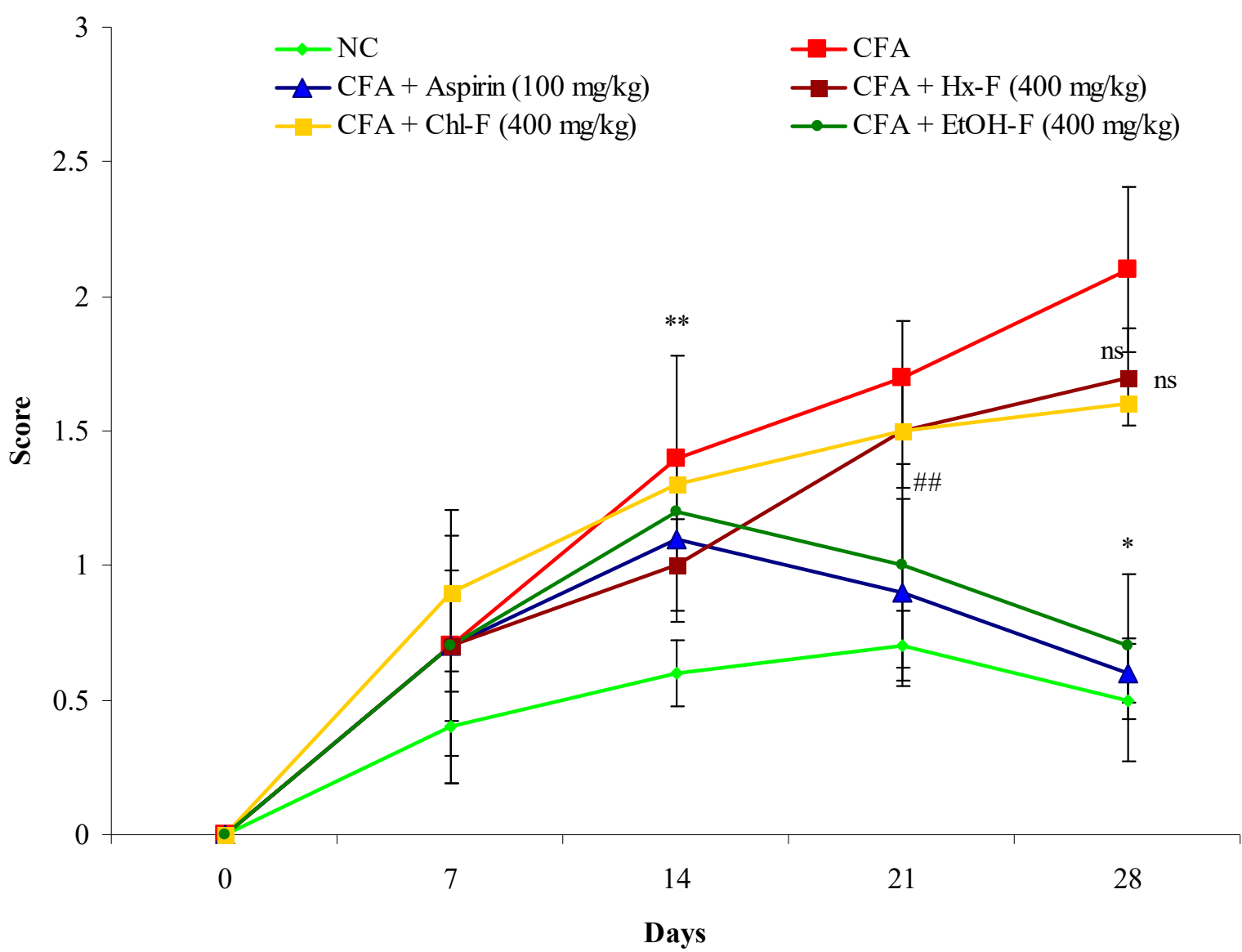

Figure 11. Effects of $S$. mangifera ethanolic fraction on CFA-induced arthritis in mice. All values are expressed as Mean $=$ $\operatorname{SEM}(n=6),{ }^{* *} p<0.01=$ significant when compared with group I. ${ }^{\# \#} p<0.01$ and ${ }^{*} p<0.05=$ significant when compared with group II. ${ }^{\mathrm{ns}} p>0.05$ : non-significant when compared with group II.

\section{Discussion}

To obtain insights into the mechanism of action of the major constituents, beta amyrin, beta sitosterol, and oleanolic acid [34], they were docked into the active site of COX-1, COX2 , and TNF- $\alpha$ by Glide XP docking. $\beta$-Amyrin, $\beta$-sitosterol, and oleonolic acid showed excellent binding affinity with pro-inflammatory cytokine TNF- $\alpha$. The co-crystallised ligand SPD-304 showed similar binding to that in the crystal structure, authenticating our docking protocol. SPD-304 was the first TNF- $\alpha$ antagonist to be identified, in 2005, and possesses a $K_{d}$ value of $5.36 \mu \mathrm{M}$ [24]. $\beta$-Amyrin, $\beta$-sitosterol, oleonolic acid and SPD-304 share high levels of similarity in their interactions with TNF- $\alpha$ in their corresponding bound states. A set of residues, consisting of Leu57A, Tyr59A, Gly121A, Tyr151A, Tyr59B, Tyr119B and Gly121B, is involved in hydrophobic interactions with $\beta$-amyrin, $\beta$-sitosterol, and oleonolic acid. These residues have been reported to be critical for the binding of the TNF- $\alpha$ antagonists [35].

Interestingly, for the rapid screening of vast numbers of bioactive natural compounds, in silico high-throughput ADME analysis and molecular docking screening is one excellent choice for quickly meeting this demand. These computer-aided techniques are used to explain or predict the toxicological and pharmacological effects of drugs; such studies reduce the cost and time required for experiments, as the drug discovery process is typically time-consuming and involves a huge amount of investment, and failure at any stage of bioactive drug development can lead to huge losses for an organisation. Notably, ADME study provides substantial information about the selected compounds with respect to the pharmacokinetic and toxicity profiles of compounds from plants, which can help in future drug development [36]. 
TNF alpha is responsible for inflammation when injury or other biological or mechanical processes occur. In the inflammation process, macrophage cells produce cytokinin and other proinflammatory agents in the body [37]. Nature provides numerous herbal plants that contain important bioactive phytoconstituents that can play a significant role in treatment or can be used as anti-inflammatory drugs, which has been helpful in the discovery of numerous anti-inflammatory agents [38]. Medications that are used for prevention and inhibition/blocking effects in preliminary reactions are set in a biological model by the leading cause, thus constraining established inflammation, and as a consequence, showing the established inflammation [39].

The ethanolic fraction of $S$. mangifera has the highest percentage of polyphenolic and flavonoidal compounds. DPPH ( $\alpha, \alpha$-diphenyl- $\beta$-picrylhydrazyl) is composed of stable free-radical molecules, its free radical scavenging potential is based on its electron transfer ability; when mixed with fractions, it contributes a hydrogen atom, thus changing the colour of the fractions from purple to yellow as a result of the formation of diphenyl picrylhydrazine molecule. The grade of the stain indicates the scavenging potential of the fraction [40].

Acharya et al. suggested that the presence of reductones exerts the reducing powers of the extracts by contravention of the free radical chain, followed by the provision of a hydrogen atom [41]. The reducing ability depends on the presence of free radical molecules in the extracts or compound, which exert scavenging activity by giving a hydrogen atom and inhibiting the free radical chain in the system [42]. The naturally occurring phenolic composites contribute advantageous health properties by decreasing the free radical oxygen species [43].

Sadia et al. reported that plants have phenolic, polyphenolic and flavonoidal phytoconstituents, which exert scavenging activity owing to their redox properties. This allows them to react as reducing agents, hydrogen donors and singlet oxygen quenchers [44].

Modi et al. (2019) reported that the mechanism of protein denaturation changes the tertiary and secondary structures of protein due to alteration in electrostatic forces due to hydrophobia, disulphide bonds, and hydrogen [45], and some chemical and physical agents, like alcohol, acetone, acids, alkalies, heavy metal salts, dyes [46], heat, light and pressure, can also alter the protein denaturation. Mizushima and Kobayashi, in 1968, reported that the inflammatory drugs salicylic acid, phenylbutazone, etc., had a dose-dependent impact on thermally induced protein denaturation. Similarly, the protein denaturation ability of S. mangifera fractions has also been shown to be concentration dependent [47]. At the site of inflammation, the ethanolic fraction of $S$. mangifera probably reduces the release of the lysosomal content of neutrophils. These neutrophil constituents may include proteinases and bactericidal enzymes, whereby extracellular release may cause further inflammation and damage to the tissue [48]. Protein denaturation is a major factor for RA, causing the generation of auto antigens on a different order, and there is a linkage between hydrophobic electrostatic and disulphide denaturation [49]. In the present study, the in vitro assay of protein denaturation demonstrated the inhibition of protein denaturation in S. mangifera ethanolic fractions. According to this, the ethanolic fraction of S. mangifera could be helpful for protection against protein denaturation and auto antigen production, which are responsible for RA. The findings of this study are reported on the basis of protein denaturation assays using fresh hen and bovine serum albumin. These findings are in contrast with previous predictive research in which the extracts and standard revealed inhibition of protein denaturation in a dose-dependent manner [50].

The leukocyte proteinase has a significant role in the enhancement of tissue damage through inflammatory responses, and a substantial level of defence is conferred by proteinase inhibitors [51].

Proteinases play a significant role in the progression of tissue damage throughout the inflammatory processes. Several researchers have suggested that a significant level of protection is provided by the proteinase inhibitors [52]. It has already been mentioned in 
the literature that flavonoids isolated from plant sources possess significant antioxidant and anti-inflammatory activities [53].

The allopathic system of medicine can produce harmful side effects in living systems. The various anti-inflammatory (Ibuprofen, etoricoxib, corticosteroids, etc.) and antirheumatic drugs like methotrexate and hydroxyl chloroquine suphasalazine play important roles in life-threatening side effects [54]. In western and eastern countries, the use of herbal medicine is in extremely high demand by the public due to its compatibility with other products, and its lack of life-threating side effects or complaints [55]. Various studies have documented that herbal medicine can play an important role in the management of rheumatoid arthritis [54].

Therapeutic effects include anti-arthritic potential and antioxidant properties, and therefore the antioxidant actions of the $S$. mangifera fractions were assessed using the two parameters DPPH and reducing power-scavenging methods in order to maintain the equilibrium between free radical and antioxidants. Disturbances in this equilibrium destroy the cellular component and cause oxidative stress due to the generation of free radical species. Many diseases, such as inflammatory disorders and arthritic disease, are the result of oxidative stress, arising from free radical species. These reactive oxygen species react with organic supermolecules like lipids, proteins and DNA in the cells of living organism and produce harmful effects [56]. Herbal plants have many bioactive phytoconstituents, including flavonoids, phenolics, lignins, etc., which have the capability of fighting or scavenging the free radicals and providing protection against free radicals and reactive oxygen species [57].

CFA administered in the experimental rodents caused inflammation, mainly in the form of joint remodelling, synovial membrane infiltration and severe inflammation. These features resemble those of rheumatoid arthritis [58]. CFA is a commonly chosen animal model for evaluating inflammation, rheumatoid arthritis and autoimmune ailments in the context of herbal drugs. CFA-induced arthritis can be categorised into many phases, starting with the induction phase (no validation), through to early synovitis, followed my synovitis with devastation of joints [31]. In the early stages of arthritis, inflammation develops due to the release of prostaglandins, whereas when auto antibodies are produced, a secondary stage develops. The production of inflammatory mediators like IL-6 and TNF- $\alpha$ show a critical role in the advancement of joint disorder, bone distortion, pain, and tenderness [59].

The reduction in paw diameter indicated reduction in inflammatory mediators, suggesting that the drug has anti-inflammatory effects in CFA-induced arthritis [60]. In this study, the group II (toxic control) animals exhibited continued swelling for 28 days due to cellular incursion, with constant oedema occurring, in contrast to the normal group I animals. However, in the ethanolic-fraction-treated group VI animals, maximum swelling was noticed at up to 7 days, with a reduction in inflammation beginning from day 8 , in contrast with the group II animals. In this study, we found that these parameters were suitable for measuring the efficiency of anti-arthritic medications [35].

In this study, S. mangifera demonstrated a reduction in joint inflammation and arthritis index, meaning that the immunosuppressive and the anti-inflammatory properties are differentiated [59]. The S. mangifera alcoholic fraction resulted in a comparative decline in the index and protection against morphological alterations. These changes were due to a reduction in swelling, while redness and secondary growth were inhibited due to its anti-arthritic potential [61]. The use of herbal drugs is met with better tolerance, and with fewer adverse effects. Drug discovery in the field of phytoconstituents obtained from natural sources could be advantageous for the pharmaceutical market as well as patient compliance.

\section{Conclusions and Future Perspective}

There are a number of plants that contain phytochemicals, which play an important role in human life and provide beneficial effects. The plant $S$. mangifera is a well-known 
plant possessing different phytoconstituents, e.g., $\beta$ sitosterol, $\beta$ amyrin and oleonolic acid. The ethanolic fraction of the plant is a good adjuvant in the present armamentarium. Therefore, it could be a beneficial agent for the management of inflammation and arthritis. The results of docking studies support the in vivo and in vitro data, showing that the active constituents of the plant interface with chain A and B of TNF- $\alpha$. The ADME studies show that among the phytoconstituents, gallic acid shows the best ADME properties, and the compound did not cross the blood-brain barrier. The in vivo data reveal the beneficial effects of the alcoholic fraction of $S$. mangifera with respect to inhibiting the free radical scavenging assay, and inhibition of protein denaturation by inhibiting the proteinase enzymes. This evidence shows that the alcoholic fraction of S. mangifera has good anti-arthritic and anti-inflammatory potential, and thus could be used in arthritis management and as a potent novel drug delivery agent. By using phytoconstituents for the management of disease, we can avoid the side effects of synthetic drugs.

Author Contributions: Conceptualization; M.K., M.H.A., A.I.F.; data curation; M.K.; Formal analysis; M.K., S.S.A.; Funding acquisition; A.A. (Abuzer Ali); Investigation; M.K., A.S.; O.A.; Methodology; M.K., Project administration; A.A. (Amena Ali); Resources; M.A.; Software; O.A.; Supervision; M.K.; Validation; O.A., M.A.; Visualization; S.S.A., A.S.A.A.; Writing-original draft; M.K., A.S.; Writing-review \& editing; M.K., A.S. All authors have read and agreed to the published version of the manuscript.

Funding: Abuzer Ali is thankful to Taif University Researchers Supporting Project Number (TURSP2020/124), Taif University, Taif, Saudi Arabia.

Acknowledgments: Abuzer Ali is thankful to Taif University Researchers Supporting Project Number (TURSP-2020/124), Taif University, Taif, Saudi Arabia.

Conflicts of Interest: The authors declare that they have no known competing financial interests or personal relationships that could have appeared to influence the work reported in this paper.

\section{References}

1. Sowjanya, R.; Shankar, M.; Sireesha, B.; Naik, E.A.; Yudharaj, P.; Priyadarshini, R.J. An overview on inflammation and plant having anti-inflammatory activity. Int. J. Phytopharm. Res. 2017, 7, 25-32.

2. James, P.B.; Wardle, J.; Steel, A.; Adams, J. Traditional complementary and alternative medicine use in Sub-Saharan Africa: A systematic review. BMJ Glob. Health 2018, 3, e000895. [CrossRef]

3. Marquardt, P.; Seide, R.; Vissiennon, C.; Schubert, A.; Birkemeyer, C.; Ahyi, V.; Fester, K. Phytochemical characterization and in-vitro anti-inflammatory, antioxidant and antimicrobial activity of Combretum collinum Fresen leaves extracts from Benin. Molecules 2020, 25, 288. [CrossRef]

4. Castro-Santos, P.; Diaz-Pena, R. Genetics of rheumatoid arthritis: A new boost is needed in Latin American populations. Rev. Bras. Reum. 2016, 56, 171-177. [CrossRef] [PubMed]

5. Zhang, Q.; Yu, Y.; Li, J.; Guan, Y.; Huang, J.; Wang, Z.; Zhang, Z.; Zhang, W.; Guo, J.; Li, J.; et al. Anti-arthritic activities of ethanol extracts of Circaea mollis Sieb. \& Zucc. (whole plant) in rodents. J. Ethnopharmacol. 2018, 225, 359-366. [PubMed]

6. Aloke, C.; Ibiam, U.A.; Orji, O.U.; Ugwuja, E.I.; Ezeani, N.N.; Aja, P.M.; Obasi, N.A. Anti arthritic potentials of ethanol and aqueous extracts of stem bark of Cleistopholis patens on complete Freund's adjuvant-induced rheumatoid arthritis in rats. $J$. Ayurveda Integr. Med. 2021, 12, 28-34. [CrossRef] [PubMed]

7. Ofman, J.J.; Badamgarav, E.; Henning, J.M. Utilization of nonsteroidal anti-inflammatory drugs and antisecretory agents: A managed care claims analysis. Am. J. Med. 2004, 116, 835-842. [CrossRef]

8. Hollman, P.C.H. Absorption, bioavailability and metabolism of flavonoids. Pharm. Biol. 2004, 42, 74-83. [CrossRef]

9. Brothersen, C.; McMahon, D.J.; Legako, J.; Martini, S. Comparison of milk oxidation by exposure to LED and fluorescent light. J. Dairy Sci. 2016, 99, 2537-2544. [CrossRef]

10. Murphy, M.P. How mitochondria produce reactive oxygen species. Biochem. J. 2009, 417, 1-13. [CrossRef]

11. Khalid, M.; Alqarni, M.H.; Foudah, A.I.; Akhtar, J.; Shoaib, A.; Alam, P. Evaluation of free radical scavenging potential of different bioactive fractions present in Boerhavia diffusa Linn. root extract: An in-vitro approach. J. Pharm. Res. Int. 2020, 32, 99-107. [CrossRef]

12. Anonymous. The Wealth of India, A Dictionary of Indian Raw Materials Publication and Information Directorate; CSIR: New Delhi, India, 1992; Volume 10, pp. 19-21.

13. Kritikar, K.R.; Basu, B.D. Indian Medicinal Plants; International book distributors: Dehradune, India, 1975; Volume III, pp. 672-675.

14. Tandon, S.; Rastogi, R.P. Studies on the chemical constituents of Spondias pinnata. Planta Med. 1976, 29, 190. [CrossRef] [PubMed] 
15. Rastogi, R.P.; Mehrotra, B.N. Compendium of Indian Medicinal Plant; CDRI Lucknow \& National Institute of Science communication: New Delhi, India, 1979; Volume I \& II, pp. 379 \& 643.

16. Jain, S.K.; Hajra, P.K.; Shampru, R. A survey of edible plants in bazzars of Meghalaya. Bull. Bot Surv. 1977, 2, $29-34$.

17. Valsaraj, R.; Pushpangadan, P.; Smitt, U.W.; Adsersel, A.; Nyman, U. Antimicrobial screening of selected medicinal plants from India. J. Ethnopharmacol. 1997, 58, 75-83. [CrossRef]

18. Itokawa, H.; Hirayama, F.; Tsuruoka, S.; Mizuno, K.; Nitta, A. Studies on antitumor activity of Indonesian medicinal plants. Shoyakugaku Zasshi 1990, 44, 58-62.

19. Rao, G.B.; Raju, N.J. Investigation of hepatoprotective activity of Spondias pinnata. Int. J. Pharm. Sci. Res. 2010, 1, 193-198.

20. Kandali, R.; Kumar, B.K. Evaluation of nutraceutical potentiality of a minor fruit of Assam-Spondias pinnata Kurz. In The Souvenir cum Abstract of "Vale Addition of Bio-Resources of NE India, Post-Harvest Technology and Cold Chain"; Department of Botany, Guwahati University: Guwahati, India, 2006; p. 99.

21. Barua, U.; Hore, D.K.; Sarma, R. Wild edible plants of Majuli and Darrang districts of Assam. Indian J. Tradit. Knowl. 2007, 6, 191-194.

22. Sidhu, R.S.; Lee, J.Y.; Yuan, C.; Smith, W.L. Comparison of cyclooxygenase-1 crystal structures: Cross-talk between monomers comprising cyclooxygenase-1 homodimers. Biochemistry 2010, 49, 7069-7079. [CrossRef]

23. Orlando, B.J.; Lucido, M.J.; Malkowski, M.G. The structure of ibuprofen bound to cyclooxygenase-2. J. Struct. Biol. 2015, 189, 62-66. [CrossRef]

24. He, M.M.; Smith, A.S.; Oslob, J.D.; Flanagan, W.M.; Braisted, A.C.; Whitty, A.; Cancilla, M.T.; Wang, J.; Lugovskoy, A.A.; Yoburn, J.C.; et al. Small-molecule inhibition of TNF-alpha. Science 2005, 310, 1022-1025. [CrossRef]

25. Friesner, R.A.; Murphy, R.B.; Repasky, M.P.; Frye, L.L.; Greenwood, J.R.; Halgren, T.A.; Sanschagrin, P.C.; Mainz, D.T. Extra precision glide: Docking and scoring incorporating a model of hydrophobic enclosure for protein-ligand complexes. J. Med. Chem. 2006, 49, 6177-6196. [CrossRef]

26. Egan, W.J.; Merz, K.M.; Baldwin, J.J. Pridiction of drug absorption using multivariate statistic. J. Med. Chem. 2000, 43, 3867-3877. [CrossRef]

27. Viji, V.; Helen, A. Inhibition of lipoxygenases and cyclooxygenase-2 enzymes by extracts isolated from Bacopa monniera (L.) Wettst. J. Ethnopharmacol. 2008, 118, 305-311. [CrossRef]

28. Liyana-Pathirana, C.M.; Shahidi, F. Antioxidant activity of commercial soft and hard wheat (Triticum aestivum L.) as affected by gastric pH conditions. J. Agric. Food Chem. 2005, 53, 2433-2440. [CrossRef] [PubMed]

29. Khalid, M.; Siddiqui, H.H.; Fareed, S. Free radical scavenging and total phenolic content of Saccharum spontaneum L. root extracts. Int. J. Res. Pharm. Chem. 2011, 1, 1160-1166.

30. Hina, I.; Rose, C. In-vitro anti-inflammatory and antiarthritic activity of Pergularia daemia Leaves and Roots. Int. J. Drug Dev. Res. 2018, 10, 10-13.

31. Dharmalingam, S.R.; Chidambaram, K.; Ramamurthy, S.; Nadaraju, S. Effects of nanosuspension and inclusion complex techniques on the in-vitro protease inhibitory activity of naproxen. Braz. J. Pharm. Sci. 2014, 50, 165-171. [CrossRef]

32. Jubie, S.; Jawahar, N.; Koshy, R.; Gowramma, B.; Murugan, V.; Suresh, B. Anti-arthritic activity of bark extracts of Alangium salviifolium Wang. Rasayan J. Chem. 2008, 1, 433-442.

33. Patil, M.V.K.; Kandhare, A.D.; Bhise, S.D. Anti-arthritic and anti-inflammatory activity of Xanthium srtumarium L. ethanolic extract in Freund's complete adjuvant induced arthritis. Biomed. Aging Pathol. 2012, 2, 6-15. [CrossRef]

34. Arif, M.; Rahman, M.A.; Imran, M.; Khalid, M.; Khushtar, M. An insight of Spondias mangifera Willd: An underutilized medicinal plant with immense nutraceutical and therapeutic potentials. Int. J. Res. Pharm. Sci. 2015, 6, 17-26.

35. Chen, S.; Feng, Z.; Wang, Y.; Ma, S.; Hu, Z.; Yang, P.; Chai, Y.; Xie, X. Discovery of novel ligands for TNF- $\alpha$ and TNF Receptor-1 through structure-based virtual screening and biological assay. J. Chem. Inf. Model. 2017, 57, 1101-1111. [CrossRef]

36. Mahanthesh, M.T.; Ranjith, D.; Raghavendra, Y.; Jyothi, R.; Narappa, G.; Ravi, M.V. Swiss ADME prediction of phytochemicals present in Butea monosperma (Lam) Taub. J. Pharmacol. Phytochem. 2020, 9, 1799-1809.

37. Jung, C.; Jung, H.; Shin, Y.; Park, J.; Jun, C. Eleutherococcus senticosus extract attenuates LPS-induced iNOS expression through the inhibition of Akt and JNK pathways in murine macropage. J. Etnopharmacol. 2007, 113, 183-187. [CrossRef]

38. Barbara, O.; Correa, H.O.; Azevedo, E.P.C.; Padua, R.M.; Oliveira, V.L.S.; Oliveira, T.H.C.; Daiane-Boff Dias, A.C.F.; De Souza, D.G.; Amaral, F.A.; Teixeira, M.M.; et al. In-vitro TNF- $\alpha$ Inhibitory Activity of Brazilian Plants and Anti-Inflammatory Effect of Stryphnodendron adstringens in an Acute Arthritis Model. Evid. Based Complementary Altern. Med. 2016, 2016, 1-15. [CrossRef]

39. Naik, S.; Sheth, U. Inflammatory process and screening methods for anti-inflammatory agents-A review. J. Postgrad. Med. 1976, $22,5-21$.

40. Onoja, S.O.; Omeh, Y.N.; Ezeja, M.I.; Chukwu, M.N. Evaluation of the in-vitro and in-vivo Antioxidant Potentials of Aframomum melegueta methanolic seed extract. J. Trop. Med. 2014, 2014, 159343. [CrossRef] [PubMed]

41. Acharya, S.; Dash, G.K.; Mondal, S.; Dash, S.K. Antioxidative and antimicrobial study of Spondias mangifera Willd root. Int. J. Pharm. Pharm. Sci. 2010, 2, 68-71.

42. Atere, T.G.; Akinloye, O.A.; Ugbaja, R.N.; Ojo, D.A.; Dealtry, G. In-vitro antioxidant capacity and free radical scavenging evaluation of standardized extract of Costus afer leaf. Food Sci. Hum. Wellness 2018, 7, 266-272. [CrossRef]

43. Sharma, A.K.; Gangwar, M.; Chaturvedi, A.P.; Sinha, A.S.; Tripathi, Y.B. Comparative analysis of phenolic and flavonoid content of Jatropha curcas Linn. Plant. Arch. 2012, 12, 823-826. 
44. Shakeel, S.; Khan, U.; Gul, S.; Sheikh, Z.A.; Zaidi, S.F.; Lateef, M. Evaluation of in vitro antioxidant capacity and reducing potential of polyherbal drug. Entoban. Afr. J. Pharm. Pharmacol. 2015, 9, 982-987.

45. Modi, C.M.; Bhatt, P.R.; Pandya, K.B.; Patel, H.B.; Patel, U.D. Comparative evaluation of in vitro anti-inflammatory activity of different extracts of selected medicinal plants from Saurashtra region, Gujarat, India. Int. J. Curr. Microbiol. Appl. Sci. 2019, 8 , 1686-1698. [CrossRef]

46. Mann, G. Chemistry of the Proteins; Macmillan and Co. Limited: London, UK; New York, NY, USA, 1906; pp. 336-344.

47. Mizushima, Y.; Kobayashi, M. Interaction of anti-inflammatory drugs with serum proteins, especially with some biologically active proteins. J. Pharm. Pharmacol. 1968, 20, 169-173. [CrossRef]

48. Chou, C.T. The antiinflammatory effect of an extract of Tripterygium wilfordii Hook F on adjuvant-induced paw oedema in rats and inflammatory mediators' release. Phytother. Res. 1997, 11, 152-154. [CrossRef]

49. Phusricom, S.; Chatuphonprasert, W.; Monthakantirat, O.; Pearaksa, P.; Jarukamjorn, K. Alternanthera sessilis and Alternanthera bettzickiana improved superoxide dismutase and catalase activities in the livers of ovariectomized mice. J. Appl. Biopharm. Pharm. 2013, 1, 64-71.

50. Sunmathi, D.; Sivakumar, R.; Ravikumar, K. In-vitro antiinflammatory and antiarthritic activity of ethanolic leaf extract of Alternanthera sessilis (L.) R. BR. ex DC and Alternanthera philoxeroides (Mart.) Griseb. Int. J. Adv. Pharm. Biol. Chem. 2016, 5, 109-115.

51. Rastogim, S.; Iqbal, M.S.; Ohri, D. In-vitro study of anti-inflammatory and antioxidant activity of some medicinal plants and their interrelationship. Asian J. Pharm. Clin. Res. 2018, 11, 195-202. [CrossRef]

52. Chandra, S.; Chatterjee, P.; Dey, P.; Bhattacharya, S. Evaluation of in-vitro anti-inflammatory activity of coffee against the denaturation of the protein. Asian Pac. J. Trop. Biomed. 2012, 2, 178-180. [CrossRef]

53. Gunathilake, K.D.P.P.; Ranaweera, K.K.D.S.; Rupasinghe, H.P.V. Analysis of rutin, carotene, and lutein content and evaluation of antioxidant activities of six edible leaves on free radicals and reactive oxygenspecies. J. Food Biochem. 2018, 42, e12579. [CrossRef]

54. Singh, S.; Nair, V.; Gupta, Y. Antiarthritic activity of majoon suranjan (a polyherbal Unani formulation) in rat. Indian J. Med. Res. 2011, 134, 384. [PubMed]

55. Balasubramaniam, L.; Manivannan, R.; Paramaguru, R.; Mazumder, P.M.; Vijayakumar, M. Evaluation of anti-inflammatory and antioxidant activities of stem bark of Todalia asiatica (L) lam. using different experimental models. Pharmacologia 2012, 3, 144-149.

56. Ghosh, S.; Derle, A.; Ahire, M.; More, P.; Jagtap, S.; Phadatare, S.D.; Patil, A.B.; Jabgunde, A.M.; Sharma, G.K.; Shinde, V.S.; et al. Phytochemical analysis and free radical scavenging activity of medicinal plants Gnidia glauca and Dioscorea bulbifera. PLoS ONE 2013, 8, e82529. [CrossRef]

57. Karagoz, A.; Artun, F.T.; Ozcan, G.; Melikoglu, G.; Anil, S.; Kultur, S.; Sutlupınar, N. In-vitro evaluation of antioxidant activity of some plant methanol extracts. Biotechnol. Biotechnol. Equip. 2015, 29, 1184-1189. [CrossRef]

58. Zheng, C.J.; Zhao, X.X.; Ai, H.W.; Lin, B.; Han, T.; Jiang, Y.P.; Xing, X.; Qin, L.P. Therapeutic effects of standardized Vitex negundo seeds extract on complete Freund's adjuvant induced arthritis in rats. Phytomedicine 2014, 21, 838-846. [CrossRef] [PubMed]

59. Gautam, R.K.; Sharma, S.; Sharma, K.; Gupta, G. Evaluation of Antiarthritic Activity of Butanol Fraction of Punica granatum Linn. Rind Extract Against Freund's Complete Adjuvant-Induced Arthritis in Rats. J. Environ. Pathol. Toxicol. Oncol. 2018, 37, 53. [CrossRef]

60. Rajendran, R.; Kumar, K.E. Anti-arthritic activity of Premna serratifolia Linn., wood against adjuvant induced arthritis. Avicenna J. Med. Biotechnol. 2010, 2, 101. [PubMed]

61. Uttra, A.M.; Shahzad, M.; Shabbir, A.; Jahan, S.; Bukhari, I.A.; Assiri, A.M. Ribes orientale: A novel therapeutic approach targeting rheumatoid arthritis with reference to proinflammatory cytokines, inflammatory enzymes and anti-inflammatory cytokines. $J$. Ethnopharmacol. 2019, 237, 92-107. [CrossRef] 